\title{
Structural or dispositional? An experimental investigation of the experience of winning in social casino games (and impulsivity) on subsequent gambling behaviors
}

\author{
HYOUN S. KIM ${ }^{1 *}$, MATTHEW ROCKLOFF ${ }^{2}$, DANIEL S. MCGRATH ${ }^{1}$, MICHAEL J. A. WOHL ${ }^{3}$ and DAVID C. HODGINS ${ }^{1}$ \\ ${ }^{1}$ Department of Psychology, University of Calgary, Calgary, Canada \\ ${ }^{2}$ Department of Psychology and Public Health, Central Queensland University, Branyan, QLD, Australia \\ ${ }^{3}$ Department of Psychology, Carleton University, Ottawa, Canada
}

(Received: March 26, 2019; revised manuscript received: June 29, 2019; second revised manuscript received: July 23, 2019; accepted: August 7, 2019)

\begin{abstract}
Background and aims: In the present research, we experimentally investigated whether the experience of winning (i.e., inflated payout rates) in a social casino game influenced social casino gamers' subsequent decision to gamble for money. Furthermore, we assessed whether facets of dispositional impulsivity - negative and positive urgency in particular - also influenced participants' subsequent gambling. Methods: Social casino gamers who were also current gamblers $(N=318)$ were asked to play a social casino game to assess their perceptions of the game in exchange for \$3. Unbeknownst to them, players were randomly assigned to one of three experimental conditions: winning ( $n=110)$, break-even ( $n=103)$, or losing $(n=105)$. After playing, participants were offered a chance to gamble their $\$ 3$ renumeration in an online roulette game. Results: A total of 280 participants $(88.1 \%)$ elected to gamble, but no between-condition variation in the decision to gamble emerged. Furthermore, there were no differences in gambling on the online roulette between condition. However, higher levels of both negative and positive urgency increased the likelihood of gambling. Finally, impulsivity did not moderate the relationship between experience of winning and decision to gamble. Conclusion: The results suggest that dispositional factors, including impulsive urgency, are implicated in the choice to gamble for social casino gamers following play.
\end{abstract}

Keywords: social casino games, inflated payout rates, gambling, impulsivity, urgency

\section{INTRODUCTION}

Social casino games (i.e., free-to-play simulated gambling games such as Slotomania) are an immensely popular form of entertainment. Current estimates suggest that there are over 81 million daily users, and this number is growing (see Veselka, Wijesingha, Leatherdale, Turner, \& EltonMarshall, 2018). Unlike traditional forms of gambling, the outcome of social casino games are not determined by chance with a built-in operator margin, but rather, they are programmed to maximize player enjoyment (Gainsbury, Hing, Delfabbro, \& King, 2014). Moreover, social casino players "risk" free virtual credits on the outcome of the game rather than real money. For these reasons, social casino games are not classified as gambling activities. Yet, they mimic the look, feel, and playing experience of real money gambling (Bramley \& Gainsbury, 2015). As a result, some researchers have expressed concern that social casino games may be a gateway to gambling (King \& Delfabbro, 2016; Wohl, Salmon, Hollingshead, \& Kim, 2017).

There is now a nascent, yet growing body of empirical evidence to suggest that social casino games may influence the migration to real money gambling. The association between social casino gaming and gambling was first provided by Kim, Wohl, Salmon, Gupta, and Derevensky (2015) who found that $26 \%$ of social casino gamers (who have never gambled online) reported migrating to online gambling over a 3-month longitudinal investigation. Furthermore, social casino games may also influence the migration to gambling among adolescents (e.g., Dussault et al., 2017; Hayer, Kalke, Meyer, \& Brosowski, 2018). For example, although it is difficult to separate out selection from exposure effects, in a large sample of adolescents who had previously never gambled $(N=1,220)$, engaging in simulated forms of gambling at baseline was associated with a $57 \%$ increase in having gambled for real money in a 1-year follow-up (Dussault et al., 2017).

In addition to being a potential gateway to gambling, social casino games may also increase gambling among people who already gamble (Gainsbury, Russell, King, Delfabbro, \& Hing, 2016; Hollingshead, Kim, Wohl, \& Derevensky, 2016).

* Corresponding author: Hyoun S. Kim; Department of Psychology, University of Calgary, Admin Building 240, 2500 University Dr. NW, Calgary, AB T2N 1N4, Canada; Phone: +1 403210 9580; E-mail: hyoun.kim@ucalgary.ca

This is an open-access article distributed under the terms of the Creative Commons Attribution-NonCommercial 4.0 International License, which permits unrestricted use, distribution, and reproduction in any medium for non-commercial purposes, provided the original author and source are credited, a link to the CC License is provided, and changes - if any - are indicated. 
Gainsbury et al. (2016) found that over $25 \%$ of people reported their gambling had increased as a direct result of playing social casino games. In addition, gamblers who played these games prior to age of 13 years also indicated that they gambled more frequently in adolescence (Rockloff et al., 2018). In a 6-month (24-week) trial, Rockloff et al. (2018) found that gamblers who played social casino games for 1 week were more likely to gamble for money in the following week, even while controlling for gambling in that prior week. Although an increasing number of studies have found an association between playing social casino games and gambling, the current literature is limited due to researchers' reliance on participants' selfreported engagement. The current research used an experimental design to provide a more objective assessment of the link by measuring social casino gaming and gambling behavior in vivo.

\section{Factors influencing the social casino gaming-gambling relationship}

In a recent literature review of the relation between simulated gambling products (including social casino games) and monetary gambling, Armstrong, Rockloff, Browne, and $\mathrm{Li}$ (2018) identified that the higher payout rates (i.e., winning more than one typically would when compared to real money gambling) in simulated forms of gambling is a risk factor for future monetary gambling. This is of concern given that one third of online gambling sites that offered practice sessions to players (i.e., demostration periods) had a payout rate over $100 \%$ (some had a payout rate as high as 520\%; Sévigny, Cloutier, Pelletier, \& Ladoucer, 2005). In an experimental investigation, Bednarz, Delfabbro, and King (2013) found that participants who were randomly assigned to a demonstration period prior to gambling on an online roulette were more likely to make riskier bets compared to those who were not assigned to a demo period. Interestingly, however, there were no differences in persistence in gambling between participants in the demo period who were assigned to a standard $(-10 \%)$ or an inflated $(+40 \%-60 \%)$ payout condition. These results were in line with a subsequent study by Frahn, Delfabbro, and King (2015) who found that an inflated payout rate $(+50 \%)$ during a demonstration period was associated with riskier bets compared to a standard rate $(90 \%)$, but once again was not associated with persistence in gambling.

To our knowledge, although no study has examined the effects of playing social casino games that have an inflated payout rate on subsequent gambling, some evidence of this relation was uncovered during a focus group study conducted by Kim, Wohl, Gupta, and Derevensky (2017). Specifically, some young adult gamblers expressed that their experience of winning on social casino games was an important factor that influenced their desire to transition to online gambling. That is, some participants expressed that winning in social casino games increased their belief that they had "skills" that could be successfully applied to monetary gambling. This inflated perception of skill was reported as a reason for their transition to gambling - they came to the belief that their winning in social casino games could be translated to winning while gambling for money.
Taken together, there is preliminary support that the experience of winning on simulated forms of gambling may be an important factor in promoting real money gambling.

Dispositional characteristics of the player may also influence the migration to social casino gaming as well as increasing future gambling among social casino gamers who already gamble. Several researchers have put forth the supposition that social casino games may influence gambling particularly among those who are vulnerable to the lures of gambling (King \& Delfabbro, 2016; Wohl, Salmon, et al., 2017). Specifically, impulsivity - the tendency to act rashly and without forethought (Hodgins \& Holub, 2015) has been proposed as one potential vulnerability factor that may influence the social casino gaming-gambling relationship (King \& Delfabbro, 2016). Impulsivity is a multidimensional construct and consists of dispositional, choice, and response components (MacKillop et al., 2016). While predominant theories of gambling have associated impulsivity (in general) with gambling (e.g., Pathways Model; Blaszczynski \& Nower, 2002), recent research has begun to examine different aspects of impulsivity and its relation to gambling. This is because not all facets of impulsivity may be associated with gambling (Brevers et al., 2012). Importantly for the present research, negative urgency, a facet of dispositional impulsivity (Lynam, Smith, Whiteside, \& Cyders, 2006), may be of particular importance. Negative urgency is the tendency to act rashly when experiencing strong negative emotions. In other words, people may use gambling as way to exert control. Specifically, gambling may be used to escape distress, such as symptom of depression (i.e., dark flow; Dixon et al., 2018). In this sense, people may use gambling as to reduce their arousal to negative affect. Unfortunately, people who are prone to impulsive actions, including turning to addictive behaviors to exert control when distressed may be at risk of development of addictive disorders, including gambling and video gaming (see Kim \& Hodgins, 2018). Indeed, negative urgency has been robustly associated with both video gaming (Billieux et al., 2015) and gambling (MacLaren, Fugelsang, Harrigan, \& Dixon, 2011).

Recently, studies have suggested that positive urgency, which is the tendency to act rashly when experiencing strong positive emotions, may also be associated with problematic gambling. This is because a function of addictive behaviors may be to regulate positive emotions by maintaining or enhancing them (Cyders \& Smith, 2008). Providing support for this supposition, positive urgency has been associated with problematic gambling in student, community, and clinical samples (Canale, Scacchi, \& Griffiths, 2016; Haw, 2017; Kim, Poole, Hodgins, McGrath, \& Dobson, 2019). In this sense, gambling can be considered as a way to increase arousal, especially among those who may find gambling highly rewarding (i.e., reinforcement sensitivity theory; see Bijttebier, Beck, Claes, \& Vandereycken, 2009). Given that social casino games share characteristics of both video gaming and gambling, and both may be used to exert control with negative emotions, negative urgency may be a specific facet of impulsivity that is characteristic of participants who engage in gambling following social casino gaming. Furthermore, positive urgency may also 
be associated with the decision to gamble following social casino gaming given the recent associations between positive urgency and gambling.

\section{OVERVIEW OF THIS STUDY}

In the current research, we investigated whether the experience of winning in a social casino game influences social casino gamers' decision to gamble following play. Although some research suggests social casino gaming as a facilitator of gambling, the existing research on this phenomenon has relied on the self-reported association between social casino games and gambling. Overreliance on self-reports can skew associations because people are often poor estimators of their gambling behavior (see Wohl, Davis, \& Hollingshead, 2017). Furthermore, individuals may not be able to differentiate between games that simulate gambling (e.g., social casino games) and gambling games played for real money (Parke, Wardle, Rigbye, \& Parke, 2013). Thus, the valid measurements of simulated forms of gambling and real money gambling are complex and challenging for empirical investigation. We contend that experimental investigations that manipulate the outcome of social casino game play, specifically the experience of winning may provide a more objective understanding of the social casino gaminggambling association. This is because the experience of winning on social casino games has been noted as a potential mechanism that may influence the social casino gaming-gambling association (Kim et al., 2017).

To directly test whether the experience of winning in a social casino game influenced monetary gambling, social casino gamers who also engaged in gambling were randomly assigned to one of three experimental conditions: winning, break-even, and losing. Participants were then provided an opportunity to engage in real money gambling. We recruited social casino gamers who also gambled given the significant portion of players who engage in both. For example, Gainsbury et al. (2016) found that almost all social casino gamers $(90.8 \%)$ also reported engaging in gambling activities. In addition, as research has shown that negative urgency is associated with both gambling (MacLaren et al., 2011) and video gaming (Billieux et al., 2015), and the association between positive urgency and gambling (Kim et al., 2019), we assessed whether facets of impulsivity, in particular negative and positive urgency, also influenced the decision to gamble following engagement with a social casino game.

Based on the existing literature, it is difficult to hypothesize whether inflated payout rates on social casino games influence gambling. This is because Bednarz et al. (2013) and Frahn et al. (2015) provided mixed support for the effects of inflated payout rates found on demo sites and subsequent gambling. On the other hand, focus groups with young online gamblers indicated the inflated payout rate on social casino games as a reason for their transition to online gambling (Kim et al., 2017). As the aim of the present research was to examine the experience of winning on social casino games, as opposed to demo sites per se, we hypothesized that participants who were assigned to the winning condition would be more likely to opt to gamble with their compensation compared to those who were randomly assigned to either the break-even condition and the losing condition. Second, it was hypothesized that social casino gamers who elected to gamble would report greater levels of negative and positive urgency compared to those who did not elect to gamble.

In the spirit of transparency and open science, we report our power analysis, all manipulations, data exclusions, and measures collected in the present experiment.

\section{METHODS}

\section{Participants and procedures}

An apriori power analysis was conducted to determine our sample size based on a number of factors. First, we calculated the sample size based on the smallest effect size that would be constituted as being meaningful; specifically, the percentage increase in the number of social casino gamers who decide to gamble following social casino gaming play. To this end, we first estimated the proportion of social casino gamers in the control conditions (break-even or losing) who would be willing to gamble. Twenty-six percent was chosen as the base rate based on previous findings of social casino gamers who migrated to gambling (Kim et al., 2015). Next, we determined a $20 \%$ increase in willingness to gamble in the experimental condition as being meaningful. Thus, using Brant's sample size calculator (http://www. stat.ubc.ca/ rollin/) for a $\chi^{2}$ test $p=.05$ with a minimum power of .80 and the above values, a sample size of 90 per cell was required $(N=270)$.

Participants were recruited using TurkPrime (Litman, Robinson, \& Abberbock, 2017; www.turkprime.com), a research platform that was designed specifically to integrate with Amazon's Mechanical Turk (MTurk; www.mturk. com). There is a growing body of empirical studies that support the use of MTurk in addiction research (Kim \& Hodgins, 2017; Strickland \& Stoops, 2019), including in web-based behavioral paradigms (Schluter, Kim, \& Hodgins, 2018). In line with best practices (Chandler \& Paolacci, 2017), we used a two-step recruitment process on MTurk to ensure our sample consisted of our target population, that is current social casino gamers who also engaged in gambling. Specifically, we first used a brief screening instrument to assess whether participants engaged in social casino games and gambling activities in the past 3 months. All participants were provided $\$ 0.25$ for completion of the screening instrument.

To identify social casino gamers, participants were asked to select from a number of statements describing their social gaming and gambling habits. Social games were defined as games that could be played on mobile devices and on social media sites such as Facebook. We informed participants that social games may also include social casino games, which are gambling-styled games where a player does not spend real money on the outcome of the game (e.g., Slotomania and Double Down Casino) but rather risks virtual credits. Participants were also asked about their gambling habits, which we defined as any activity where a player bets or risks something of value (typically money) on an activity with an unknown outcome. We then provided examples of gambling 
activities including casino games, slot machines, sports betting, scratch tickets, and lotteries. In addition, those who indicated playing social casino games were asked to identify what were social casino games played in the past 3 months, which included the most popular social casino games during the study as well as several fake social casino games. Participants who indicated playing fake social casino games were not invited to complete the main study. Participants who indicated engaging in real social casino games and gambling in the past 3 months were then invited to our main study.

Eligible participants who granted consent completed measures assessing demographic characteristics and their social casino gaming and gambling behaviors. Moreover, participants completed the following measures for exploratory purposes: social casino gaming motives, reward sensitivity to social casino games, binge social casino gaming, problematic social casino gaming use, gambling cognitions, and problem gambling severity. Impulsivity (UPPS-P) was also measured as a test of our dispositional hypothesis that negative urgency should be related to the choice to gamble. Detailed descriptions of the measures used for this study are noted below.

Thereafter, participants played Lucky Lolly Slots, a social casino gaming application developed for research purposes by one of the authors (MR). Specifically, participants were informed that the purpose of the study was to assess peoples' perceptions of a new social casino game called Lucky Lolly Slots. In other words, participants were not informed of the true nature of the study, which was to investigate the experience of winning on social casino games on subsequent gambling. However, participants were debriefed regarding the true nature of the study upon completion of the entire study (i.e., upon termination of the real money gambling task). To assess their perceptions, participants were asked to play Lucky Lolly Slots for a minimum of $10 \mathrm{~min}$ to provide their impressions. Ten minutes, which corresponds to an average of 100 spins, was chosen as the duration for several reasons. First, best practices with MTurk recommends studies to be as short as possible to increase attention and quality of data (Hauser, Paolacci, \& Chandler, 2019). Second, in our previous experience with Lucky Lolly Slots, we found that MTurk participants generally would engage with Lucky Lolly Slots for 7-10 min.

Unbeknownst to the participants, they were randomly assigned to one of three experimental conditions with differing win rates: winning condition $(115 \%)$, break-even condition (100\%), and losing condition (85\%). As no study has systematically investigated the payout rates of social casino games, the percentages of the winning and losing conditions were chosen based on payout rates of slot machines reported by Harrigan and Dixon (2009). The break-even condition was added as a control condition to further assess whether it is in fact the experience of winning (rather than experience of losing) that may have affected participants decision to gamble following social casino play and is in line with previous studies, which have included a break-even condition (Bednarz et al., 2013). Moreover, objectively, a break-even win rate over 100 spins is a realistic outcome, since natural volatility could easily produce this result. To simulate the playing experience of social casino games, participants would experience a series of wins and losses until they reach their target payout rate at the 90 th spin (i.e., $115 \%, 100 \%$, or $85 \%$ ), which corresponded to $10 \mathrm{~min}$ of gameplay. Participants would then float within $5 \%$ of their payout rate until the 250th spin, before experiencing a series of losses until there were no credits remaining. All participants, regardless of condition, were given 1,000 credits at the start of play. Similar to previous studies (Frahn et al., 2015), participants were restricted in their play such that they bet 9 credits per spin, and players could win between 10 credits to 250 credits, in addition to experiencing losses.

After playing Lucky Lolly Slots, participants were asked a series of questions regarding their perceptions of the game and were also asked whether they had won, lost, or brokeeven as an attention check. Participants' playing behaviors, including the number of spins and ending number of credits, were behaviorally tracked and stored on secure servers.

To assess whether the experience of winning influenced social casino gamers' decision to gamble, participants were then offered an opportunity to gamble with their remuneration of $\$ 3.00$ in an online roulette game with a minimum bet of 1 credit $(\$ 0.01)$ to a maximum of 50 credits $(\$ 0.50)$. Participants were informed that they did not have to gamble and could simply complete the study. Those who chose to gamble were explicitly informed that the online roulette was real money gambling and they could win more than their initial wager but could also lose all their remuneration. They were also informed that they could stop gambling at any point. Similar to Lucky Lolly Slots, participants were unaware that the outcome of online roulette (also developed by MR for research purposes) was predetermined such that participants would on average break-even, which was confirmed when examining the ending credits of the online roulette $(M=298.26$ cents, $S D=48.30, \quad \min =35$, $\max =436$ ). Participants' gambling behaviors in the online roulette game, including the number of spins, maximum bet for a single spin, and total amount wagered, were also behaviorally tracked and stored on secure servers. The behavioral tracking data for both Lucky Lolly Slots and online roulette were then matched with participants' selfreport items in our analyses.

All participants were compensated with a total of $\$ 6$ regardless of whether they chose to gamble, or the number of credits lost when they discontinued gambling on the online gambling game.

\section{Measures}

Gambling variables. Several gambling-related variables were assessed. Whether participants chose to gamble in the online roulette game served as a binary outcome (i.e., gambled vs. did not gamble). Participants' total number of spins, highest bet size, and the total amount they wagered in the online roulette game were also used as measures of gambling intensity. Problem gambling severity was assessed using the 9-item Problem Gambling Severity Index (PGSI; Ferris \& Wynne, 2001). The PGSI is one of the most widely used measures of gambling severity and assesses both behaviors and consequences related to problem gambling. The items are anchored from 0 (never) to 3 (almost always) with higher scores indicating greater 
problem gambling severity. The Cronbach's $\alpha$ from the present sample was $(\alpha=.91)$.

Impulsivity. Impulsivity was assessed using the short version of the UPPS-P (SUPPS-P; Cyders, Littlefield, Coffey, \& Karyadi, 2014). The SUPPS-P contains 20 items and assesses 5 facets of dispositional impulsivity: (a) negative urgency (i.e., the tendency to act rashly under intense negative emotions), (b) positive urgency (i.e., the tendency to act rashly under intense positive emotions), (c) sensation seeking (i.e., the tendency to seek out activities that are exciting), (d) premeditation (i.e, thinking through an action including its consequences before acting), and (e) perseverance (i.e, the ability to persist at a given task). The items are anchored from 1 (strongly agree) to 4 (disagree strongly). The $\alpha$ s from the present sample ranged from .80 to .85 . The SUPPS-P shares similar intercorrelations and factor structure when compared to the full-length version (Cyders et al., 2014).

\section{Statistical analyses}

We first conducted $\chi^{2}$ analyses and analysis of variance (ANOVA) to confirm that random assignment led to similar characteristics across the experimental conditions, both in terms of demographics and variables of interest. Thereafter, a $\chi^{2}$ analysis was conducted to assess whether the decision to gamble (a dichotomous outcome) differed between the three experimental conditions. Separate ANOVAs were conducted to assess whether the three experimental conditions differed in regard to the number of spins, the total amount wagered, and the highest bet size in the online roulette game. A $t$-test was conducted to examine differences in the facets of impulsivity among participants who decided to gamble compared to those who did not decide to gamble following social casino gaming. Two supplemental analyses were also conducted. First, a $\chi^{2}$ analysis assessed whether a more pronounced payout rate influenced social casino gamers decision to gamble. Second, moderation analyses were conducted using PROCESS V3 Model 1 (Hayes, 2017) to test whether impulsivity moderated the relationship between experience of winning and subsequent gambling.

\section{Ethics}

The study procedures were carried out in accordance with the Declaration of Helsinki. The Institutional Review Board of the University of Calgary and Central Queensland University approved the study. All participants were informed about the study and all provided informed consent.

\section{RESULTS}

\section{Preliminary results}

A total of 599 participants met the eligibility criteria and were invited to complete the main study. Of the 599 respondents, 281 persons were removed from analysis for the following reasons: 145 for incomplete response (e.g., did not play Lucky Lolly Slots), 77 participants played Lucky Lolly Slots for fewer than 90 spins (contrary to instruction),
41 failed the attention check, 16 participants were missing their online gambling data, and 2 participants' self-report and behavioral tracking data could not be matched. Consequently, the final sample consisted of 318 participants.

In regard to our experimental conditions, 110 participants were assigned at random to the winning condition, 103 to the break-even condition, and 105 to the losing condition. As expected, there were substantial differences in the ending credit for Lucky Lolly Slots across the three conditions, $F(315)=85.11, p \leq .001$ with a mean ending credit of $1,086.01(+8.60 \%)(S D=177.42)$ in the inflated payout condition, $979.83(-2.02 \%)(S D=145.44)$ in the breakeven condition, and $784.69(-21.53 \%)(S D=187.43)$ in the losing condition. Participants were free to choose when to discontinue play following the 90th spin, which resulted in the actual average payouts modestly deviating from our anticipated ending balances of 1,150, 1,000, and 850, respectively. As would be expected from random assignment, no significant or substantial differences existed between the three conditions on any demographic variables, problem gambling severity or any of the facets of impulsivity (Table 1).

\section{Main results}

Inflated payout rates. Of the 318 participants, $280(88.05 \%)$ decided to engage in online gambling following social casino game play. Contrary to our hypothesis, there was no significant difference in this choice between the conditions: winning condition $(88.18 \%)$, break-even condition $(89.32 \%)$, or the losing condition $(86.67 \%), \chi^{2}(2)=0.35$, $p=.839$, Cramer's $V=0.03$. Similarly, there were no differences across the three groups in regard to number of spins in the online roulette game, $F(2,277)=0.56, p=.575$, $\eta^{2}=0.004$, highest bet size, $F(2,277)=2.55, p=0.080$, $\eta^{2}=0.02$, or the total amount wagered, $F(2,277)=0.54$, $p=.585, \eta^{2}=0.004$ (Table 2). Finally, there were no differences in the ending credits reached between participants who chose to gamble $(M=950.23, S D=218.13)$ compared to those who did not $(M=966.05, S D=160.49)$, $t(316)=0.43, p=.667, d=0.08$.

Impulsivity. Participants who elected to engage in online gambling (i.e., roulette) following social casino game play reported significantly greater levels of negative urgency $(M=2.44, S D=0.79$ vs. $M=2.12, S D=0.73), t(316)=$ $-2.39, p=.018, d=0.42$ and positive urgency $(M=2.06$, $S D=0.71$ vs. $M=1.78, \quad S D=0.66), \quad t(316)=-2.31$, $p=.022, d=0.41$ compared to those who did not engage in online gambling. On the contrary, no differences were found between those who elected to gamble on lack of perseverance $\left(M_{\text {yes }}=1.60, S D_{\text {yes }}=0.52\right.$ vs. $M_{\text {no }}=1.52$, $\left.S D_{\text {no }}=0.47\right), t(316)=-0.91, p=.364, d=0.16$; lack of premeditation $\left(M_{\mathrm{yes}}=1.78, S D_{\mathrm{yes}}=0.53\right.$ vs. $M_{\mathrm{no}}=1.61$, $\left.S D_{\mathrm{no}}=0.54\right), \quad t(316)=-1.85, \quad p=.066, \quad d=0.32 ; \quad$ or sensation seeking $\left(M_{\text {yes }}=2.54, S D_{\text {yes }}=0.75\right.$ vs. $M_{\text {no }}=$ 2.76, $\left.S D_{\mathrm{no}}=0.78\right), t(316)=1.74, p=.083, d=0.29$.

\section{Supplemental analyses}

Given the final balance for winning condition was below $115 \%$, we reran our analysis with the top $20 \%$ of 
Table 1. Demographic characteristics, impulsivity, and problem gambling severity of the total sample and comparison between the experimental conditions

\begin{tabular}{|c|c|c|c|c|c|c|c|c|}
\hline Characteristic & $\begin{array}{l}\text { Total sample } \\
\qquad(N=318)\end{array}$ & $\begin{array}{c}\text { Win } \\
\text { condition } \\
(n=110)\end{array}$ & $\begin{array}{c}\text { Break-even } \\
\text { condition } \\
(n=103)\end{array}$ & $\begin{array}{l}\text { Losing } \\
\text { condition } \\
(n=105)\end{array}$ & $\chi^{2}$ & $F$ & $p$ & ES \\
\hline Age [years, mean $(S D)]$ & $37.3(11.0)$ & $36.4(9.8)$ & $37.8(11.8)$ & $37.7(11.6)$ & & 0.50 & .607 & $0.003^{\mathrm{a}}$ \\
\hline Gender $[n(\%)]$ & & & & & 1.480 & & .477 & $0.068^{\mathrm{b}}$ \\
\hline Male & $142.0(44.7)$ & $46.0(41.8)$ & $51.0(49.5)$ & $45.0(42.9)$ & & & & \\
\hline Female & $176.0(55.3)$ & $64.0(58.2)$ & $52.0(50.5)$ & $60.0(57.1)$ & & & & \\
\hline Ethnicity $[n(\%)]$ & & & & & 0.415 & & .813 & $0.036^{\mathrm{b}}$ \\
\hline Caucasian & $266.0(83.6)$ & $90.0(81.8)$ & $87.0(84.5)$ & $89.0(84.8)$ & & & & \\
\hline Non-Caucasian & $52.0(16.4)$ & $20.0(18.2)$ & $16.0(15.5)$ & $16.0(15.2)$ & & & & \\
\hline Marital status $[n(\%)]^{\mathrm{c}}$ & & & & & 0.018 & & .991 & $0.007^{\mathrm{b}}$ \\
\hline In a relationship & $147.0(46.2)$ & $51.0(46.4)$ & $48.0(46.6)$ & $48.0(45.7)$ & & & & \\
\hline Not in a relationship & $171.0(53.8)$ & $59.0(53.6)$ & $55.0(53.4)$ & $57.0(54.3)$ & & & & \\
\hline Highest level of education $[n(\%)]$ & & & & & 0.857 & & .931 & $0.037^{\mathrm{b}}$ \\
\hline High school or less & $90.0(28.3)$ & $30.0(27.3)$ & $30.0(29.1)$ & $30.0(28.6)$ & & & & \\
\hline Post-secondary below a Bachelor's & $108.0(34.0)$ & $35.0(31.8)$ & $35.0(34.0)$ & $38.0(36.2)$ & & & & \\
\hline Bachelor's degree or higher & $120.0(37.7)$ & $45.0(40.9)$ & $38.0(36.9)$ & $37.0(35.2)$ & & & & \\
\hline Employment status $[n(\%)]$ & & & & & 1.143 & & .887 & $0.060^{\mathrm{b}}$ \\
\hline Employed & $216.0(67.9)$ & $77.0(70.0)$ & $69.0(67.0)$ & $70.0(66.7)$ & & & & \\
\hline Unemployed & $68.0(21.4)$ & $24.0(21.8)$ & $22.0(21.4)$ & $22.0(21.0)$ & & & & \\
\hline Other $^{d}$ & $34.0(10.7)$ & $9.0(8.2)$ & $12.0(11.7)$ & $13.0(12.4)$ & & & & \\
\hline Household income $[n(\%)]$ & & & & & 1.157 & & .561 & $0.060^{\mathrm{b}}$ \\
\hline Less than $\$ 50,000$ & $162.0(50.9)$ & $58.0(52.7)$ & $55.0(53.4)$ & $49.0(46.7)$ & & & & \\
\hline$\$ 50,000$ or more & $156.0(49.1)$ & $52.0(47.3)$ & $48.0(46.6)$ & $56.0(53.3)$ & & & & \\
\hline \multicolumn{9}{|l|}{ Impulsivity } \\
\hline Negative urgency & $2.40(0.80)$ & $2.52(0.73)$ & $2.34(0.87)$ & $2.34(0.76)$ & & 1.86 & .157 & 0.012 \\
\hline Positive urgency & $2.03(0.71)$ & $2.03(0.72)$ & $2.10(0.79)$ & $1.94(0.61)$ & & 1.34 & .263 & 0.008 \\
\hline Perseverance (lack of) & $1.59(0.52)$ & $1.63(0.53)$ & $1.61(0.53)$ & $1.54(0.49)$ & & 0.85 & .428 & 0.005 \\
\hline Premeditation (lack of) & $1.76(0.53)$ & $1.75(0.53)$ & $1.77(0.57)$ & $1.75(0.49)$ & & 0.04 & .964 & 0.000 \\
\hline Sensation seeking & $2.57(0.75)$ & $2.66(0.81)$ & $2.46(0.74)$ & $2.56(0.69)$ & & 1.90 & .151 & 0.012 \\
\hline Problem gambling severity & $3.97(5.01)$ & $4.07(4.95)$ & $4.07(5.61)$ & $3.77(4.44)$ & & 0.13 & .883 & 0.001 \\
\hline
\end{tabular}

Note. ES: effect size; $S D$ : standard deviation.

${ }^{a}$ Partial eta squared. ${ }^{\mathrm{b}}$ Cramer's $V$. ${ }^{\mathrm{c}}$ In a relationship includes participants who are in in a common-law relationship or are legally married. Not in a relationship includes participants who are single (never married), separated, divorced, or widowed. ${ }^{\mathrm{d}}$ Other employment status includes participant who are students, retired, homemakers, or disabled.

Table 2. Online gambling behaviors following social casino gaming play and comparison between the three conditions

\begin{tabular}{|c|c|c|c|c|c|c|c|c|}
\hline Measure & $\begin{array}{l}\text { Total sample } \\
(N=318)\end{array}$ & $\begin{array}{l}\text { Win condition } \\
\quad(n=110)\end{array}$ & $\begin{array}{c}\text { Break-even } \\
\text { condition } \\
(n=103)\end{array}$ & $\begin{array}{l}\text { Losing } \\
\text { condition } \\
(n=105)\end{array}$ & $\chi^{2}$ & $F$ & $p$ & ES \\
\hline Chose to play roulette $[n(\%)]$ & & & & & 0.35 & & .839 & $0.03^{\mathrm{a}}$ \\
\hline Yes & $280(88.05)$ & 97 (88.18) & $92(89.32)$ & 91 (86.67) & & & & \\
\hline No & $38(11.95)$ & $13(11.82)$ & $11(10.68)$ & $14(13.33)$ & & & & \\
\hline Total number of spins [mean $(S D)]$ & $8.60(10.55)$ & $8.42(9.55)$ & $7.89(9.56)$ & $9.51(12.40)$ & & 0.56 & .575 & $0.004^{b}$ \\
\hline Highest single bet [mean $(S D)]^{\mathrm{a}}$ & $33.46(20.95)$ & $35.57(20.85)$ & $29.45(21.29)$ & $35.27(20.35)$ & & 2.55 & .080 & $0.020^{\mathrm{b}}$ \\
\hline $\begin{array}{l}\text { Total bet amount across all spins } \\
\text { [mean }(S D)]\end{array}$ & $206.36(353.77)$ & $209.55(349.70)$ & $177.80(374.50)$ & $231.84(337.96)$ & & 0.54 & .585 & $0.004^{\mathrm{b}}$ \\
\hline
\end{tabular}

Note. For each spin, participants were allowed to bet a minimum of 1 credit and a maximum of 50 credits valued at $\$ 0.01$ per credit. ES: effet size; $S D$ : standard deviation.

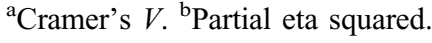

participants with highest credits in winning condition (+18.95\%) compared to the top $20 \%$ of participants with lowest credits in the losing condition $(-47.32 \%)$. There were no statistically significant differences between winning and losing condition on participants' decision to gamble, $\chi^{2}(2)=0.41, p=.522$, which was $95.5 \%$ and $90.5 \%$, respectively. To test whether impulsivity moderated the relationship between experience of winning and participants subsequent decision to gamble, two separate moderation analyses were conducted with negative and positive 
urgency. Negative and positive urgency were chosen as potential moderators given their significant association with the decision to gamble following social casino gaming. The interaction effect was not significant for either negative urgency $(p=.95)$ or positive urgency $(p=.24)$. These results suggest that urgency was not a statistically significant moderator in the decision between experience of winning on social casino games and subsequent decision to gamble.

\section{DISCUSSION}

Advances in technology have significantly influenced the ways in which people engage in gambling, including simulated forms of gambling such as social casino games. In the present research, we aimed to add to the growing understanding of the social casino gaming-gambling association by being the first study to experimentally investigate whether structural characteristics of social casino games, and specifically how the experience of winning influenced social casino gamers' decision to gamble following social casino game play. Furthermore, we also examined whether differences in dispositional characteristics - negative and positive urgency in particular - existed between social casino gamers who elected to gamble compared to social casino gamers who did not and whether impulsivity moderated the association between the experience of winning on social casino games and gambling.

Failing to confirm our hypothesis, and in line with the broader literature on experience of winning on simulated gambling games (Bednarz et al., 2013; Frahn et al., 2015), participants who were randomly assigned to the winning condition were not significantly more likely to elect to engage in online gambling compared to participants who were randomly assigned to the break-even condition or losing condition. These findings remained the same when the analyses were conducted with a subset of participants with the highest amount of credits in the winning condition and the lowest amount of credits in the losing condition. A potential reason for this finding could be because that the large majority of participants decided to engage in online gambling (88\%). This finding is perhaps not surprising given that our sample consisted of participants who engaged in both social casino gaming and gambling activities. As such, our results can only speak to increases in gambling following social casino gaming among people who engage in both, rather than whether the experience in winning influences the migration to gambling among non-gambling social casino gamers. Future research could examine whether the experience of winning in social casino games influences a subsequent choice to gamble among social casino gamers who do not otherwise engage in gambling (i.e., exclusive social casino gamers).

In addition, we examined only the influence of winning on subsequent gambling behaviors on only one type of social casino game: social casino slots. Slot machines are a purely chance-based gambling activity, and thus the results of our research may not generalize to other social casino games that simulate more skill-based games, such as social casino poker. Lastly, other structural characteristics may be important in understanding the social casino gaming-gambling link. For example, rather than the experience of winning in general, it is plausible that social casino games may increase the number of jackpots and free spins to enhance players perception of personal skill and luck, which may then influence social casino gamers to engage in gambling activities. At present, this is merely speculation and would need empirical support.

In line with our hypothesis, participants who elected to engage in online gambling following social casino game play reported higher levels of impulsivity, specifically negative and positive urgency. However, impulsivity did not moderate the association between experience of winning and gambling. The finding that impulsivity was associated with gambling following social casino gaming is not surprising given the prominent role of impulsivity in models of problem gambling (e.g., Pathways Model; Blaszczynski \& Nower, 2002) and the vast majority of empirical investigations reported a link between impulsivity and problem gambling (Nower \& Blaszczynski, 2006). Yet, not every dimension of impulsivity is associated with gambling. Our results provide further support for that urgency may be a particularly important component of impulsivity for gambling and other addictive disorders (Kim \& Hodgins, 2018).

Taken together, the results of our present research suggest that dispositional characteristics may be an important consideration in understanding the social casino gaming-gambling association. This finding is in line with theories that suggest one potential negative consequence of exposure to social casino games is the transition to gambling among those who are vulnerable, specifically those who may be high in trait levels of impulsivity (King \& Delfabbro, 2016). A potential implication of our results is that educational initiatives regarding playing experiences can be improved to enhance player safety. Specifically, social casino gaming operators should highlight to players that they are likely to win more on social casino games compared to real money gambling to mitigate its influence on future gambling choices. Moreover, educational initiatives may do well to emphasize the potential link between social casino gaming and gambling in general, and particularly outline the link for social casino gamers who are the most vulnerable.

\section{Limitations}

A limitation of the present research was that our sample consisted of participants who engaged in both social casino games and online gambling. Although our results may have greater generalizability given that the majority of social casino gamers also engage in gambling (Gainsbury et al., 2016), our results cannot speak to whether inflated payout rates influence willingness to gamble among social casino gamers who do not engage in gambling. Second, the inflated payout rate of $+15 \%$ was relatively low. It is possible that a greater payout rate (e.g., 150\%) is needed to obtain an effect on subsequent decision to gamble. Future research would do well to examine whether more extreme payout rates may influence social casino gamers subsequent decision to gamble for real money. Third, although $\$ 3$ is a relatively high remuneration for MTurk studies, it is nevertheless a 
low amount to wager, which may have resulted in the high uptake to engage in online roulette following social casino game play. Indeed, it is possible that participants may have lacked sufficient motivation whether they kept or lost their renumeration. Thus, future studies should examine the influence on the decision to gamble following social casino gaming with a higher budget replication, specifically with larger bets and higher wins. Fourth, we assessed only one potential dispositional characteristic (i.e., impulsivity) that may be of importance in the social casino gaming-gambling relationship. Future studies assessing other dispositional and situational characteristics that may influence the social casino gaming-gambling relationship would be informative. Fifth, the duration of roulette play was relatively short. Furthermore, while the roulette was preprogrammed to break-even, participants may have experienced varying sequence of wins or losses, which may have influenced their decision to stop gambling. That said, participants were not restricted in their gambling to enhance ecological validity. Relatedly, participants were asked to switch tasks from a social casino slot game to roulette gambling, which may have decreased the generalizability of the manipulation. Finally, not all participants who met the eligibility criteria played Lucky Lolly Slots. MTurk participants, and particularly those who chose to participate in this study, may not have been entirely representative of the broad group of individuals who play social casino games and gamble. Future research examining the influence of social casino games on the decision to gamble with more diverse populations (e.g., adolescents) would be highly informative.

\section{CONCLUSIONS}

In conclusion, we found no evidence to suggest that, among people who engage in both social casino gaming and gambling, the experience of winning (small amounts) on social casino games influences social casino gamers' choice to gamble immediately following play. However, participants who reported higher levels of negative and positive urgency, facets of impulsivity that have been associated with problematic gambling, were more likely to gamble after playing a social casino game. Thus, the results suggest that dispositional characteristics are important predictors of future choices to gamble among people who play both social casino games and gambling games.

Funding sources: This research was funded by a large grant (\#80) to the authors from the Alberta Gambling Research Institute (AGRI). AGRI had no part in the design, analyses, or dissemination of the present manuscript.

Authors' contribution: All authors contributed to the conceptualization of the research. MR designed and created the social casino gaming and gambling applications. HSK conducted the data analysis and wrote the first draft of the manuscript. All authors edited and contributed significantly to the manuscript.
Conflict of interest: HSK has received scholarships from AGRI in support of his doctoral studies. He has also received grants from AGRI. DCH and DSM salaries are supported in part by AGRI and have also received grants from AGRI. MR has received research grants from the Queensland Treasury, the Victorian Treasury, the Victorian Responsible Gambling Foundation, the New Zealand Ministry of Health, the NSW Department of Industry and Trade, the Department of Social Services, AGRI and Gambling Research Australia. MJAW has received gambling-related research funding from provincial granting agencies in Canada. He has also received direct and indirect research funds from the gambling industry in Canada, United States, and Sweden. In addition, he has served as a consultant for the gambling industry in Canada, United States, and Australia. Funds have also been awarded by federal granting agencies in Canada and Australia for research unrelated to gambling. A detailed list can be found on his curriculum vitae (http://carleton.ca/bettermentlabs/ wp-content/uploads/CV.pdf).

Acknowledgements: The authors would like to thank Diandra Leslie from the University of Calgary for her help in the data collection.

\section{REFERENCES}

Armstrong, T., Rockloff, M., Browne, M., \& Li, E. (2018). An exploration of how simulated gambling games may promote gambling with money. Journal of Gambling Studies, 34(4), 1165-1184. doi:10.1007/s10899-018-9742-6

Bednarz, J., Delfabbro, P., \& King, D. (2013). Practice makes poorer: Practice gambling modes and their effects on real-play in simulated roulette. International Journal of Mental Health and Addiction, 11(3), 381-395. doi:10.1007/s11469-012-9422-1

Bijttebier, P., Beck, I., Claes, L., \& Vandereycken, W. (2009). Gray's reinforcement sensitivity theory as a framework for research on personality-psychopathology associations. Clinical Psychology Review, 29(5), 421-430. doi:10.1016/j. cpr.2009.04.002

Billieux, J., Thorens, G., Khazaal, Y., Zullino, D., Achab, S., \& Van der Linden, M. (2015). Problematic involvement in online games: A cluster analytic approach. Computers in Human Behavior, 43, 242-250. doi:10.1016/j.chb.2014.10.055

Blaszczynski, A., \& Nower, L. (2002). A pathways model of problem and pathological gambling. Addiction, 97(5), 487-499. doi:10.1046/j.1360-0443.2002.00015.x

Bramley, S., \& Gainsbury, S. M. (2015). The role of auditory features within slot-themed social casino games and online slot machine games. Journal of Gambling Studies, 31(4), 1735-1751. doi:10.1007/s10899-014-9506-x

Brevers, D., Cleeremans, A., Verbruggen, F., Bechara, A., Kornreich, C., Verbanck, P., \& Noël, X. (2012). Impulsive action but not impulsive choice determines problem gambling severity. PLoS One, 7(11), e50647. doi:10.1371/journal.pone. 0050647

Canale, N., Scacchi, L., \& Griffiths, M. D. (2016). Adolescent gambling and impulsivity: Does employment during high school moderate the association? Addictive Behaviors, 60, 37-41. doi:10.1016/j.addbeh.2016.04.001 
Chandler, J. J., \& Paolacci, G. (2017). Lie for a dime: When most prescreening responses are honest but most study participants are impostors. Social Psychological and Personality Science, 8(5), 500-508. doi:10.1177/1948550617698203

Cyders, M. A., Littlefield, A. K., Coffey, S., \& Karyadi, K. A. (2014). Examination of a short English version of the UPPS-P Impulsive Behavior Scale. Addictive Behaviors, 39(9), 1372-1376. doi:10.1016/j.addbeh.2014.02.013

Cyders, M. A., \& Smith, G. T. (2008). Emotion-based dispositions to rash action: Positive and negative urgency. Psychological Bulletin, 134(6), 807-828. doi:10.1037/a0013341

Dixon, M. J., Stange, M., Larche, C. J., Graydon, C., Fugelsang, J. A., \& Harrigan, K. A. (2018). Dark flow, depression and multiline slot machine play. Journal of Gambling Studies, 34(1), 73-84. doi:10.1007/s10899-017-9695-1

Dussault, F., Brunelle, N., Kairouz, S., Rousseau, M., Leclerc, D., Tremblay, J., Cousineau, M.-M., \& Dufour, M. (2017). Transition from playing with simulated gambling games to gambling with real money: A longitudinal study in adolescence. International Gambling Studies, 17(3), 386-400. doi:10.1080/14459795.2017.1343366

Ferris, J. A., \& Wynne, H. J. (2001). The Canadian Problem Gambling Index (pp. 1-59). Ottawa, ON: Canadian Centre on Substance Abuse.

Frahn, T., Delfabbro, P., \& King, D. L. (2015). Exposure to freeplay modes in simulated online gaming increases risk-taking in monetary gambling. Journal of Gambling Studies, 31(4), 1531-1543. doi:10.1007/s10899-014-9479-9

Gainsbury, S., Hing, N., Delfabbro, P. H., \& King, D. L. (2014). A taxonomy of gambling and casino games via social media and online technologies. International Gambling Studies, 14(2), 196-213. doi:10.1080/14459795.2014.890634

Gainsbury, S. M., Russell, A. M., King, D. L., , Delfabbro, P., \& Hing, N. (2016). Migration from social casino games to gambling: Motivations and characteristics of gamers who gamble. Computers in Human Behavior, 63, 59-67. doi:10.1016/j.chb.2016.05.021

Harrigan, K. A., \& Dixon, M. (2009). PAR Sheets, probabilities, and slot machine play: Implications for problem and non-problem gambling. Journal of Gambling Issues, 23(23), 81-110. doi:10.4309/jgi.2009.23.5

Hauser, D., Paolacci, G., \& Chandler, J. (2019). Common concerns with MTurk as a participant pool Evidence and Solutions. In F. R. Kardes, P. M. Herr, \& N. Schwarz (Eds.), Handbook of research methods in consumer psychology (pp. 319-336). New York, NY: Routledge.

Hayer, T., Kalke, J., Meyer, G., \& Brosowski, T. (2018). Do simulated gambling activities predict gambling with real money during adolescence? Empirical findings from a longitudinal study. Journal of Gambling Studies, 34(3), 929-947. doi:10.1007/s10899-018-9755-1

Hayes, A. F. (2017). Introduction to mediation, moderation, and conditional process analysis: A regression-based approach. New York, NY: Guilford Publications.

Haw, J. (2017). Impulsivity predictors of problem gambling and impaired control. International Journal of Mental Health and Addiction, 15(1), 154-165. doi:10.1007/s11469-0159603-9

Hodgins, D. C., \& Holub, A. (2015). Components of impulsivity in gambling disorder. International Journal of Mental Health and Addiction, 13(6), 699-711. doi:10.1007/s11469-015-9572-z
Hollingshead, S., Kim, H. S., Wohl, M. J. A., \& Derevensky, J. (2016). The social casino gaming-gambling link: Motivation for playing social casino games determines whether self-reported gambling increases or decreases among problem gamblers. Journal of Gambling Issues, 33, 52-67. doi:10.4309/ jgi.2016.33.4

Kim, H. S., \& Hodgins, D. C. (2017). Reliability and validity of data obtained from alcohol, cannabis, and gambling populations on Amazon's Mechanical Turk. Psychology of Addictive Behaviors, 31(1), 85-94. doi:10.1037/adb0000219

Kim, H. S., \& Hodgins, D. C. (2018). Component model of addiction treatment: A pragmatic transdiagnostic treatment model of behavioral and substance addictions. Frontiers in Psychiatry, 9, 406. doi:10.3389/fpsyt.2018.00406

Kim, H. S., Poole, J. C., Hodgins, D. C., McGrath, D. S., \& Dobson, K. S. (2019). Betting to deal: Coping motives mediate the relationship between urgency and problem gambling severity. Addiction Research \& Theory, 27(2), 95-103. doi:10.1080/16066359.2018.1455188

Kim, H. S., Wohl, M. J. A., Gupta, R., \& Derevensky, J. L. (2017). Why do young adults gamble online? A qualitative study of motivations to transition from social casino games to online gambling. Asian Journal of Gambling Issues and Public Health, 7(1), 6. doi:10.1186/s40405-017-0025-4

Kim, H. S., Wohl, M. J. A., Salmon, M. M., Gupta, R., \& Derevensky, J. (2015). Do social casino gamers migrate to online gambling? An assessment of migration rate and potential predictors. Journal of Gambling Studies, 31(4), 1819-1831. doi:10.1007/s10899-014-9511-0

King, D. L., \& Delfabbro, P. H. (2016). Early exposure to digital simulated gambling: A review and conceptual model. Computers in Human Behavior, 55, 198-206. doi:10.1016/j. chb.2015.09.012

Litman, L., Robinson, J., \& Abberbock, T. (2017). TurkPrime. com: A versatile crowdsourcing data acquisition platform for the behavioral sciences. Behavior Research Methods, 49(2), 433-442. doi:10.3758/s13428-016-0727-z

Lynam, D. R., Smith, G. T., Whiteside, S. P., \& Cyders, M. A. (2006). The UPPS-P: Assessing five personality pathways to impulsive behavior. West Lafayette, IN: Purdue University.

MacKillop, J., Weafer, J., Gray, J. C., Oshri, A., Palmer, A., \& de Wit, H. (2016). The latent structure of impulsivity: Impulsive choice, impulsive action, and impulsive personality traits. Psychopharmacology, 233(18), 3361-3370. doi:10.1007/ s00213-016-4372-0

MacLaren, V. V., Fugelsang, J. A., Harrigan, K. A., \& Dixon, M. J. (2011). The personality of pathological gamblers: A metaanalysis. Clinical Psychology Review, 31(6), 1057-1067. doi:10.1016/j.cpr.2011.02.002

Nower, L., \& Blaszczynski, A. (2006). Impulsivity and pathological gambling: A descriptive model. International Gambling Studies, 6(1), 61-75. doi:10.1080/14459790600644192

Parke, J., Wardle, H., Rigbye, J., \& Parke, A. (2013). Exploring social gambling: Scoping, classification and evidence review. UK Gambling Commission. Retrieved from http://eprints.lincoln.ac.uk/16412

Rockloff, M., Greer, N., Armstrong, T., Thorne, H., Langham, E., Browne, M., Moskovsky, N., Goodwin, B. \& Li, E. (2018). Mobile EGMs apps - The perfect substitute or the perfect storm? Melbourne, Australia: Victorian Responsible Gambling Foundation. 
Schluter, M. G., Kim, H. S., \& Hodgins, D. C. (2018). Obtaining quality data using behavioral measures of impulsivity in gambling research with Amazon's Mechanical Turk. Journal of Behavioral Addictions, 7(4), 1122-1131. doi:10.1556/ 2006.7.2018.117

Sévigny, S., Cloutier, M., Pelletier, M. F., \& Ladouceur, R. (2005). Internet gambling: Misleading payout rates during the "demo" period. Computers in Human Behavior, 21(1), 153-158. doi:10.1016/j.chb.2004.02.017

Strickland, J. C., \& Stoops, W. W. (2019). The use of crowdsourcing in addiction science research: Amazon Mechanical Turk. Experimental and Clinical Psychopharmacology, 27(1), 1-18. doi:10.1037/pha0000235
Wohl, M. J., Davis, C. G., \& Hollingshead, S. J. (2017). How much have you won or lost? Personalized behavioral feedback about gambling expenditures regulates play. Computers in Human Behavior, 70, 437-445. doi:10.1016/j.chb.2017.01.025

Wohl, M. J., Salmon, M. M., Hollingshead, S. J., \& Kim, H. S. (2017). An examination of the relationship between social casino gaming and gambling: The bad, the ugly, and the good. Journal of Gambling Issues, 35, 1-23. doi:10.4309/ jgi.2017.35.1

Veselka, L., Wijesingha, R., Leatherdale, S. T., Turner, N. E., \& Elton-Marshall, T. (2018). Factors associated with social casino gaming among adolescents across game types. BMC Public Health, 18(1), 1167. doi:10.1186/s12889-018-6069-2 